\title{
PALESTRA:
}

\section{Políticas educacionais para o ensino superior: um desafio para os cursos de música}

\author{
Liane Hentschke
}

Longe de ser um marco meramente cronológico, este final de século está sendo marcado por mudanças significativas em vários setores da sociedade, incluindo o setor educacional. Quando da minha estada na Universidade de Londres como professora visitante, em 1999, tive a oportunidade de participar de Seminários sobre as últimas reformas educacionais que lá iniciaram em 1988. Uma das questões prioritárias na pauta de educação na Inglaterra tem sido a avaliação institucional em todos os níveis: fundamental, médio e universitário. As expressões chaves são quality assurance in education e standards in education (qualidade em educação e padrões em educação).

A partir das discussões, debates e documentos do governo e das agências responsáveis pela avaliação do ensino, pôde-se perceber que a avaliação está sendo priorizada não só como um meio de planejar um ensino mais eficiente como também para atender a 
demanda de profissionais por parte da iniciativa privada. Detrás de toda esta política encontrase uma preocupação fundamental: a de aproximar a academia (leia-se Universidades e escolas) das demandas sociais, ou seja, de estabelecer uma relação estreita entre os processos de formação e os processos de consumo desta formação. Durante os muitos debates ocorridos no Institute of Education, envolvendo autoridades educacionais, políticos, representantes da iniciativa privada e acadêmicos, perpassou a idéia de que a academia está gradativamente perdendo a sua autonomia na produção e difusão de conhecimento. A retirada do estado de obrigações para com o sistema educacional nos diferentes níveis de ensino está resultando na substituição do atual modelo educacional por uma visão tecnicista e utilitária de educação ditada pela iniciativa privada ou mais amplamente, pelas demandas do mercado de trabalho.

Se estas medidas preocupam os países desenvolvidos, onde existem inúmeras possibilidades de financiamento alternativo da educação, mais preocupante tornam-se quando percebemos que estes modelos são importados de maneira indiscriminada para dentro de sistemas educacionais de muitos países em desenvolvimento. Digo isto pois o modelo de avaliação que está sendo implantado na Inglaterra é muito similar ao modelo que o Ministério da Educação está implantando no Brasil para o ensino de graduação e pós- 
graduação. Como membro da Comissão de Especialistas de Ensino de Música do Ministério da Educação há quase quatro anos, tenho presenciado de perto as mudanças que 0 governo brasileiro está propondo para o ensino superior e também para o ensino fundamental e médio. Dentre estas estão: a) o projeto de autonomia das universidades, que irá representar a quase completa retirada das obrigações do estado para com a educação superior; b) a elaboração de documentos de padrões de qualidade contendo os critérios de avaliação de ensino, e; c) a elaboração de novas diretrizes curriculares para os diversos níveis de ensino. No caso brasileiro, uma das preocupações dos educadores em geral é com relação a fragmentação e falta de articulação destas políticas entre os diferentes níveis de ensino e a falta de diálogo com a comunidade acadêmica.

A universidade está nos nossos dias diante de múltiplos desafios: de um lado temos o processo de globalização exigindo a formação de profissionais cada vez mais voltados ao mercado de trabalho, e de outro a necessidade de nos voltarmos para as necessidades regionais, até mesmo como uma forma de preservar nossa cultura e potencialidades. A globalização em termos culturais em geral e musical em particular, tem sido claramente observada através dos meios de comunicação que procuram massificar e dirigir o gosto musical das crianças e adolescentes, criando ao mesmo tempo, demarcações de territórios culturais e 
sociais através da música. Em outras palavras, o mesmo fenômeno da concomitância entre globalização e regionalização.

Com o avanço cada vez mais acelerado dos meios de comunicação, sentimo-nos compelidos a acompanhar tudo o que acontece em termos políticos, econômicos, educacionais, etc. Se há duas décadas atrás 0 grande desafio da humanidade era o acesso ao conhecimento, hoje o desafio está na seleção do conhecimento que chega até nós. Vivemos numa sociedade nova, a sociedade do conhecimento, onde o conceito 'educação para a vida' tem dominado as discussões a respeito das reformas educacionais para este novo milênio. Neste sentido aumenta a responsabilidade da universidade não só como produtora de conhecimento e propagadora de informações, mas principalmente como crítica de um conhecimento que também é produzido na sociedade. Alguns pessimistas arriscam-se em prever que a universidade nesta forma como existe hoje está prestes a ser extinta, principalmente porque ela deixou de ser o único espaço para a capacitação de profissionais. Uma das causas pode ser o reflexo da descontextualização entre as necessidades do mercado de trabalho e a insistência das universidades em se manterem autônomas na produção do conhecimento.

Sabemos que hoje as empresas e indústrias possuem os seus centros de formação profissional e de produção de conhecimento através do fomento à pesquisa científica. De 
certa forma os órgãos governamentais (MEC, CAPES, CNPq, entre outros) estão procurando atender em partes esta demanda externa. Um exemplo recente é o surgimento de cursos de pós-graduação direcionados a setores empresariais, os assim chamados mestrados profissionais.

Poderíamos nos perguntar: o que estas questões têm a ver com o ensino de música? Tudo. Na medida em que este tipo de política educacional está se tornando o novo paradigma em inúmeros países, com palavras chaves do tipo avaliação, qualidade, produtividade, mercado de trabalho, entre outras, o ensino de música institucionalizado terá que se adaptar a estas mudanças. Cedo ou tarde os nossos modelos de ensino musical fundamental, médio e superior terão que sofrer uma reavaliação com base nos novos paradigmas educacionais. 0 que devemos perguntar é: será que o nosso paradigma de educação musical faz sentido diante desta nova política educacional prevista para a próxima década? Onde estaria localizado o descompasso entre o que é trabalhado na escola/universidade e o mundo musical a que o indivíduo tem acesso fora dela? Estas são algumas das questões que tem me inquietado ultimamente, e eu gostaria de utilizar este espaço para compartilhar esta inquietação que certamente não é exclusividade minha.

Em termos de Brasil, falar sobre políticas educacionais transformou-se em uma espécie de febre nacional. Jornais, televisão, radio, 
congressos, têm sido os meios mais utilizados para propagar a idéia de que a prioridade do Ministério da Educação está centrada na melhoria da qualidade de ensino em todos os níveis. Provavelmente, desde a década de 60 , não havíamos presenciado uma atenção tão grande às questões educacionais. Os debates estão, mais do que nunca, extrapolando os muros das Universidades, e com isto envolvendo os meios de comunicação e comunidade com vistas à conscientização de que educação é um problema de todos e não só de profissionais e instituiçõos diretamente envolvidos.

A partir da homologação da nova Lei de Diretrizes e Bases da Educação (LDB No. 9.394 de dezembro de 1996), grandes reformas foram e ainda estão sendo realizadas em todos os níveis de ensino:

a. no Ensino Básico, que compreende a educação infantil (0-6 anos), o ensino fundamental ( $1^{\underline{a}}$ a $8^{\underline{a}}$ série), e o ensino médio (1a a $3^{\underline{a}}$ série do II grau), com a criação de Parâmetros Curriculares Nacionais;

b. no ensino de graduação, com a criação das Diretrizes Curriculares para todos os cursos superiores, e criação e implantação dos Padrões de qualidade para avaliação dos cursos, e;

c. nos cursos de pós-graduação, com a implantação de novos sistemas de avaliação, definições e abrangências dos cursos de mestrado e doutorado, criação de mestrados profissionais, entre outros. 
Em se tratando de educação musical esta nova fase da educação brasileira, marcada pela aprovação da LDB em dezembro de 1996, está trazendo algumas consequiências imediatas, que neste momento seria difícil julgá-las como sendo positivas ou negativas. Necessitamos de fóruns de debates como este, em âmbito regional, e outros em âmbito nacional. Este Encontro, com a temática voltada às questões curriculares, é de extrema relevância considerando o momento histórico que estamos vivendo em termos de educação no Brasil. É importante que a área de educação musical esteja se voltando às questões de ordem política, e por que não dizer, de ordem econômica, as quais interferem diretamente na questão da sobrevivência e status da área na nossa sociedade.

Em outros momentos, durante os últimos três anos, eu tenho enfatizado a necessidade de utilizar os canais políticos competentes para lutar por maiores espaços de atuação junto aos órgãos governamentais, sejam estes de âmbito federal, estadual e/ou municipal. Cito como exemplo a criação da CEE/MÚSICA, junto à SESu, resultante do desmebramento da CEE/ARTES em 4 novas Comissões. Aliado a esta conquista, esteve sempre presente entre os membros da antiga CEE/ARTES, e agora da CEE/MÚSICA, a tentativa de buscar uma maior integração entre a SESu e a Secretaria de Ensino Fundamental SEF. Como membro da Comissão de Especialistas eu tenho observado e alertado quanto a desarticulação entre as Secretarias do MEC, uma 
vez que políticas são traçadas em cada uma delas, sem que se considere a interdependência entre os níveis de ensino. Enquanto a SEF está preocupada com a confecção dos PCNs para o Ensino Básico, com uma previsão de áreas de conhecimento e disciplinas que devem fazer parte dos currículos em todo o país, a SESu, preocupa-se com a confecção de Diretrizes Curriculares delineando assim o perfil do profissional de ensino superior, dentre eles os professores que irão atuar nestes níveis de ensino. Isto sem adentrar nas políticas específicas da CAPES que se concentra na gerência dos cursos de pós-graduação.

As conseqüências desta desarticulação podem ser desastrosas principalmente para a nossa área e para as demais artes, tendo em vista as mudanças que irão ocorrer nos cursos de Licenciatura em Educação Artística, os quais, após a homologação das Diretrizes terão que optar por uma área de concentração (Artes Visuais ou Artes Cênicas ou Música). Sabemos que de nada adianta haver uma reformulação nos cursos de licenciatura em artes se não houver um futuro mercado de trabalho para educadores musicais. A recíproca também é verdadeira, ou seja, não basta uma demanda de educadores musicais por parte das escolas, se os cursos de licenciatura não estiverem formando educadores musicais. Daí a necessidade de uma sintonia entre todos os níveis de ensino.

Após esta introdução eu gostaria de me concentrar no debate de alguns pontos que 
dizem respeito aos currículos do ensino de graduação e sobre o papel exercido pela pósgraduação no desenvolvimento da área no país. E por último sugerir alguns passos que poderão nos auxiliar a repensar os nossos currículos de graduação frente as novas políticas educacionais. No meu entender este recorte de graduação e pós-graduação não deixa de ser artificial, uma vez que eu percebo todos os níveis de ensino intimamente interligados.

Com relação ao ensino de música na graduação, já em 1995, por ocasião do VIII Encontro Nacional da ANPPOM, levantei algumas questões referentes à fragmentação do conhecimento musical quando considerado 0 currículo em ação no ensino superior de música no Brasil. Primeiro, com relação à dissociação existente entre o ensino de disciplinas teóricas e práticas de música, e; segundo entre a formação musical e pedagógica dos alunos de licenciatura. As considerações que apresentei partiram de relatos e observações obtidas através de contatos com professores e estudantes de diversas universidades, professores de música das escolas de I e II graus, e alunos e professores do departamento onde atuo como docente. Hoje retorno a este tema, mas desta vez para levantar uma terceira questão: a compartimentação e descontextualização das práticas educacionais nos nossos cursos de música em relação a realidade profissional que está do lado de fora das nossas salas de aula e departamentos. 
Se fizermos uma coleta de grades curriculares entre os cursos de graduação do Brasil certamente veremos uma tendência a homogeneização de conteúdos e práticas pedagógicas. Independente do curso de graduação estar localizado no Rio Grande do Sul, na Bahia ou em outra região do país, as concepções acerca do que consiste um profissional em música são quase que idênticas, assim como os currículos dos cursos. Se analisarmos os nossos currículos de graduação, veremos que estão repletos de disciplinas há muitos anos tidas como "indispensáveis" à formação de um bom músico, ou como diria Jeanneret (1993, p 47), obedecendo o antigo "modelo de conservatório". Estas disciplinas já fazem parte do senso comum no momento de estabelecer um currículo de um curso superior de música. Será que todas as sub-áreas devem ter o mesmo bloco de disciplinas? Até eu ponto estamos levando em conta as necessidades regionais em termos de mercado de trabalho? Não quero aqui postular uma posição neoliberal acerca da vinculação estreita entre formação profissional e mercado de trabalho. Por outro lado, estaríamos sendo inconseqüentes se desprezássemos esta variável. Melhor falando, na minha opinião nós estamos sendo inconseqüentes, pois os nossos currículos são tão limitados que estão excluindo uma parcela de jovens que anseiam por conhecimentos musicais diferenciados. Construímos fôrmas acadêmicas as quais tentamos impor a qualquer pessoa que deseja buscar uma formação superior na área de 
música. Devemos nos questionar se estes conhecimentos continuam sendo indispensáveis para atuação profissional em certas carreiras da área de música.

Além da descontextualização dos cursos de música temos outros problemas, tais como a fragmentação do conhecimento que é trabalhado por disciplinas. Sabemos que as disciplinas de um currículo, são divisões arbitrárias de um corpo de conhecimento, o que não quer dizer que estas sejam passíveis de serem dispensadas de maneira isolada sem considerar o que está sendo ensinado na sala ao lado, e muito menos sem saber se estas correspondem ao corpo de conhecimento necessário para a formação do profissional que desejamos preparar.

A nossa experiência diária como profissionais de ensino superior evidencia que os professores das mais diversas áreas de música acabam concentrando-se nas suas especialidades, muitas vezes ignorando o que está sendo ensinado na sala ao lado. É provável que este fenômeno seja decorrente do avanço do conhecimento e da necessidade da especialização em campos específicos do saber. Esta necessidade é manifestada pelas exigências das Instituições de Ensino Superior de que os professores devam produzir conhecimento através de pesquisas, produção artística e intelectual. Como conseqüência, exige-se dos instrumentistas que sejam exímios concertistas, dos compositores que produzam literatura 
musical, dos musicólogos que produzam literatura crítica sobre aspectos teóricos e históricos musicais e dos educadores musicais, que sejam educadores, músicos, pseudopsicólogos, sociólogos, filósofos, e sobretudo que pesquisem sobre os processos de desenvolvimento do conhecimento musical das crianças, dos adolescentes e dos adultos.

Quanto aos interesses imediatos em sala de aula, para o professor de instrumento, o que interessa é que o aluno venha a ele sem problemas de "alfabetização" em termos de teoria e percepção, o mesmo que um professor de harmonia, análise e composição espera. Para o educador musical encarregado das disciplinas pedagógicas do curso de licenciatura, interessa saber se este aluno recebeu uma formação musical básica e suficientemente ampla para poder trabalhar as questões pedagógicas, estas muitas vezes contraditórias à própria formação recebida. No entanto, pouco se sabe sobre como - aluno está construindo o conhecimento musical que a ele está sendo fornecido.

Fico perplexa quando vejo os alunos quase concluindo o curso de Licenciatura e ainda incapazes de selecionar, a partir de uma bibliografia, aquilo que é importante dentro de uma temática apresentada. Este fato é em grande parte decorrente do excesso de paternalismo por parte dos professores, o que leva à perpetuação de uma prática que se inicia no ensino fundamental. Mais estarrecedor é constatar que muitos alunos de pós-graduação 
chegam até nós com estes mesmos problemas. De uma coisa podemos estar certos: o desenvolvimento deste potencial crítico do aluno não se dará através de um currículo sobrecarregado de disciplinas teóricas e práticas e sim através de muita leitura e discussão, as quais levarão à formação do profissional com autonomia intelectual. Os sistemas tutoriais ou classes com pequenos grupos podem ser uma alternativa para um atendimento mais individualizado. Existem conteúdos a serem aprendidos que dispensam a presença do professor (treinamento auditivo, noções aprofundadas de história e teoria da música). 0 professor tem a função de situar historicamente as grandes linhas de pensamento, enquanto que a tecnologia, computadores e softwares, encarregam-se da parte de treinamento diversificado.

Quanto ao ensino de pós-graduação no país, devemos admitir que estes têm sido de fundamental importância para o desenvolvimento da área de educação musical no Brasil. A partir da década de 80 , o número de docentes com pós-graduação tem se elevado significativamente devido ao retorno de profissionais com titulação e ao surgimento dos Cursos de Pós-graduação em Música no país. Atualmente encontramos uma concentração de mestres e doutores nos cursos de música das regiões Sul, Sudeste e Nordeste, devido à concentração de cursos de pós-graduação nestas regiões. Nas demais regiões, são poucos os cursos que possuem um corpo docente com esta 
titulação. Mesmo nas regiões Sul, Sudeste, e Nordeste, ainda carecemos de profissionais com doutorado nas mais diversas sub-áreas do ensino da música, situação esta que tende a ser minimizada na medida em que as agências de fomento como CAPES e CNPq continuam financiando programas de pós-graduação a nível nacional e oferecem bolsas de estudo para cursos de pós-graduação no exterior (HENTSCHKE, 2000). A Tabela 1 apresenta a distribuição dos cursos de Pós-graduação no Brasil.

\section{Tabela 1 - DISTRIBUIÇÃO DOS CURSOS DE}

PÓS-GRADUAÇÃO NO BRASIL

\begin{tabular}{|c|c|c|c|}
\hline $\begin{array}{l}\text { REGI- } \\
\tilde{A} O\end{array}$ & INSTITUIÇÃO & $\begin{array}{l}\text { IMPLAN- } \\
\text { TAÇÃOO }\end{array}$ & $\begin{array}{l}\text { CONCEN- } \\
\text { TRAÇÃO }\end{array}$ \\
\hline $\begin{array}{l}\text { Nord- } \\
\text { este }\end{array}$ & $\begin{array}{l}\text { UFBA - Universidade } \\
\text { Federal da Bahia } \\
\text { MESTRADO } \\
\text { DOUTORADO }\end{array}$ & $\begin{array}{l}1990 \\
1997\end{array}$ & $\begin{array}{l}\text { Composição, } \\
\text { Educação } \\
\text { Musical, } \\
\text { Etnomusi- } \\
\text { cologia }\end{array}$ \\
\hline \multirow[t]{3}{*}{$\begin{array}{l}\text { Sud- } \\
\text { este }\end{array}$} & $\begin{array}{l}\text { UNIRIO - Universidade } \\
\text { do Rio de Janeiro } \\
\text { MESTRADO } \\
\text { DOUTORADO }\end{array}$ & $\begin{array}{l}1993 \\
1998\end{array}$ & $\begin{array}{l}\text { Musicologia } \\
\text { Histórica, } \\
\text { Práticas } \\
\text { Interpreta- } \\
\text { tivas }\end{array}$ \\
\hline & $\begin{array}{l}\text { UFRJ Universidade } \\
\text { Federal do Rio de } \\
\text { Janeiro } \\
\text { MESTRADO } \\
\text { DOUTORADO }\end{array}$ & $\begin{array}{l}1980 \\
1998\end{array}$ & $\begin{array}{l}\text { Composição, } \\
\text { Práticas } \\
\text { Interpreta- } \\
\text { tivas }\end{array}$ \\
\hline & $\begin{array}{l}\text { CBM - Conservatório } \\
\text { Brasileiro de Música } \\
\text { MESTRADO }\end{array}$ & 1982 & $\begin{array}{l}\text { Educação } \\
\text { Musical, } \\
\text { Etnomusi- } \\
\text { cologia, } \\
\text { Musicologia }\end{array}$ \\
\hline
\end{tabular}




\begin{tabular}{|l|l|l|l|}
\hline \multicolumn{1}{|l|}{} & $\begin{array}{l}\text { UNICAMP - } \\
\text { Universidade Estadual } \\
\text { de Campinas } \\
\text { MESTRADO }\end{array}$ & 1993 & Composição, \\
\cline { 1 - 2 } & $\begin{array}{l}\text { USP - Universidade de } \\
\text { São Paulo } \\
\text { MESTRADO }\end{array}$ & 1993 & Musicologia \\
\hline \begin{tabular}{ll|l|} 
UNESP- Universidade \\
Estadual Paulista \\
MESTRADO
\end{tabular} & 1993 & $\begin{array}{l}\text { Práticas } \\
\text { Interpreta- } \\
\text { tivas } \\
\text { Musicologia }\end{array}$ \\
\hline Sul & $\begin{array}{l}\text { UFRGS - Universidade } \\
\text { Federal do Rio Grande } \\
\text { do Sul } \\
\text { MESTRADO } \\
\text { DOUTORADO }\end{array}$ & & $\begin{array}{l}\text { Educação } \\
\text { Musical, } \\
\text { Práticas } \\
\text { Interpreta- } \\
\text { tivas, } \\
\text { Composição }\end{array}$ \\
\hline
\end{tabular}

Hoje já é possível citar alguns fatores positivos decorrentes do desenvolvimento da pós-graduação no Brasil. Primeiro, os egressos dos cursos de pós-graduação, estão gradativamente suprindo a demanda de profissionais titulados em Regiões do país que estavam ainda defazadas. Segundo, a maioria dos cursos de música no Brasil que abrigam um curso de pós-graduação, possuem uma produção artística e de pesquisa desenvolvida. Em termos de educação musical, pesquisas têm sido desenvolvidas na área de estudos curriculares, sociologia da educação musical, psicologia da música, entre outras. Estas pesquisas são financiadas por órgãos de fomento estaduais, ou federais como o CNPq. 
Estas são algumas das muitas vantagens do desenvolvimento da pós-graduação em Música no Brasil. No entanto, existem certos aspectos que ainda devem ser reavaliados e um destes é a falta de articulação entre os cursos de graduação e pós-graduação. Quando os PPGs surgiram na nossa área, estes eram vistos e mantidos como verdadeiros guetos de um saber diferenciado, onde poucas atividades eram desenvolvidas em conjunto com a graduação. $\mathrm{Na}$ minha instituição $o$ resultado foi um afastamento dos alunos de graduação da sede do PPG. Certa ocasião perguntei aos meus alunos por que eles não participavam das atividades promovidas pelo PPG tais como, colóquios e defesas de tese. Estes relataram que sentem-se constrangidos em comparecer à sede do curso.

Atualmente a CAPES está orientando os Programas de Pós-graduação no sentido de estreitar os laços entre a graduação e pósgraduação. Algumas medidas práticas estão sendo tomadas, tais como a exigência de estágio docente dos alunos de mestrado e doutorado nos cursos de graduação. Os Programas de Iniciação científica já existentes há mais tempo têm sido fundamentais para realizar a ponte entre os alunos de graduação e a capacitação inicial em pesquisa. Este treinamento é fundamental para os alunos que desejam ingressar em cursos de pós-graduação.

Muitas questões ainda poderiam ser levantadas, mas eu prefiro que estas sejam 
discutidas a partir dos participantes do Encontro. Por último, eu gostaria de sugerir algumas possíveis alternativas de como abordar a questão da reforma curricular nos cursos de graduação. Em primeiro lugar é importante iniciar um debate acerca da situação de cada curso superior em relação à demanda externa. Esta etapa diagnóstica é de fundamental importância para que se possa traçar políticas regionais de formação profissional sem perder de perspectiva o aspecto global da demanda social. Em segundo lugar, analisar o currículo atual enquanto guia e enquanto ação educacional. Como é que este "guia" está documentado e de que forma este está sendo trabalhado, ou seja, como os conhecimentos estão sendo articulados no decorrer do curso? Em um terceiro momento é importante que os cursos superiores tenham um projeto pedagógico o qual contemple uma inter-relação entre as concepções universalistas e as concepções diferencialistas (Santos, 1997, p. 35). Um projeto pedagógico que contemple a diversidade cultural e ao mesmo tempo as necessidade regionais. Neste sentido as Diretrizes Curriculares oferecem grandes áreas de conhecimento que deveriam permear os cursos no entanto sem limitar a criatividade e necessidades profissionais regionais. Em quarto lugar, deveríamos embarcar em uma discussão acerca dos paradigmas vigentes de educação musical, pois de nada adiantam novas Diretrizes e/ou novas grades curriculares, se os profissionais que atuam nas universidades 
continuam arraigados em paradigmas ultrapassados de formação musical. Neste sentido é fundamental um trabalho com o corpo docente onde a concepção de cada um seja explicitada para, a partir disto, o curso discutir alternativas de reformulação curricular. Não existe artificialidade maior do que modificar a grade curricular sem que a mentalidade dos que executam a grade seja reformulada, repensada. $E$ em quinto lugar eu diria que, como profissionais do ensino superior, temos o dever de produzir conhecimento, levá-lo à sociedade, e sobretudo mediar o processo de aquisição do conhecimento dos nossos alunos de maneira consciente e responsável pois é na nossa atividade docente que encontramos a base do tripé, pesquisa, extensão e ensino.

Como membro da CEE/MÚSICA e como uma das coordenadoras de todo o processo de construção e discussão das Diretrizes Curriculares, eu posso assegurar aos profissionais da área de música no Brasil que estes e outros temas permearam as discussões preliminares à confecção das Diretrizes curriculares. Hoje, mesmo não dispondo das Diretrizes homologadas pelo CNE, eu ficaria satisfeita em ouvir relatos sobre possíveis discussões que estejam sendo realizadas no sentido de modernizar e compatibilizar os currículos de graduação em música com as demandas deste novo milênio. 


\section{Referências bibliográficas}

HENTSCHKE, L. (org). Educação Musical em Países de Línguas Neolatinas. Porto Alegre: Editora da UFRGS. 2000.

HENTSCHKE, L. A Teoria e a Prática Sobre a Interdependência entre os Discursos Musical e Sobre Música. Anais do VIII Encontro Anual da ANPPOM. João Pessoa, Julho de 1996.

JEANNERET, N. "The preparation of secondary music teachers: old problems, new insights and possible solutions". British Journal of Music Education. Vol. 10 No. 1, 47-56, 1993. 29-44, 1995.

MINISTÉRIO DA EDUCAÇÃO/SECRETARIA DE ENSINO SUPERIOR, Divisão de Análise e de Indicadores (mimeo), 1994

SANTOS, L.L.C.P. e LOPES, J.S.M. Globalização, Multiculturalismo e Currículo. In Moreira, A. F. B. (org), Currículo: Questões Atuais. São Paulo: Papirus Editora, 1997, pp 29-38. 